ORIGINAL ARTICLE

\title{
Soil microbiota respond to green manure in organic vineyards
}

\author{
C.M.O. Longa, L. Nicola, L. Antonielli, E. Mescalchin, R. Zanzotti, E. Turco and I. Pertot \\ Research and Innovation Centre, Fondazione Edmund Mach (FEM), San Michele all' Adige (TN), Italy
}

\begin{abstract}
Keywords
bacteria, biodynamic vineyard, fungi, green manure, microbial community structure, microbial diversity, organic vineyard, soil microbiology, soil vineyard.

\section{Correspondence}

Claudia M. O. Longa, Research and Innovation Centre, Fondazione Edmund Mach (FEM), Via E. Mach 1, 38010 San Michele all'Adige (TN), Italy.

E-mail: claudia.longa@fmach.it
\end{abstract}

2017/1003: received 25 May 2017, revised 5 September 2017 and accepted 3 October 2017

doi:10.1111/jam.13606

\begin{abstract}
Aims: The aim of this work was to investigate the effects of biodynamic management with and without the addition of green manure, in comparison with organic management, on the microbiota in vineyards soil.

Methods and Results: High throughput sequencing was used to compare the taxonomic structure of the soil bacterial and fungal communities from vineyards managed with different methods (organic, biodynamic or biodynamic with green manure). Our results showed that microbial communities associated with biodynamic and organic farming systems were very similar, while green manure was the greatest source of soil microbial biodiversity and significantly changed microbial richness and community composition compared with other soils. Green manure also significantly enriched bacterial taxa involved in the soil nitrogen cycle (e.g. Microvirga sp., Pontibacter sp. and Nitrospira sp.).

Conclusions: Our results showed that the diversity and composition of the microbial communities associated with biodynamic and organic farming systems were similar, indicating that the use of biodynamic preparations 500 and 501 did not cause any significant detectable changes to the soil microbial community in the short term, while the effects of green manure were significant in soil microbiota.

Significance and Impact of the Study: The microbiological richness and structure of soil are used as a sensitive indicator of soil quality. The extension of organic/biodynamic farming, associated with green manure application, could contribute to increase the abundance of functional groups of biological and agronomical relevance and maintaining microbial biodiversity in vineyard soils.
\end{abstract}

\section{Introduction}

Since there are vineyards dating back to pre-Roman times in Europe, the grapevine offers a unique opportunity to study extremely long-term monocultures (Schlegel 1973). The physical and chemical properties of soil generally have a major effect in shaping the microbial population of vineyard soil (Corneo et al. 2013). Compared with other agro-ecosystems, vineyard soils receive lower nitrogen fertilizer input and are subjected to relatively infrequent tilling and fewer herbicide applications, which may be reflected in the composition of microbial communities (Steenwerth et al. 2008). However, in recent years, grape- growing areas have been subjected to cropping intensification. Thus, traditional vineyards planted along the contours of hills on small terraces have often been abandoned and replaced by larger plots on low to moderate slopes, with chemical fertilization and weed control, which increases grape production, but also intensifies soil degradation (Lopez-Pineiro et al. 2011). Indeed, in terms of biochemical properties, vineyard soils are usually highly degraded (Miguens et al. 2007). Long-term use of certain inorganic pesticides, in particular copper-based fungicides, has resulted in increased concentrations of heavy metals in the soil, affecting the environmental compartments of soil (Komarek et al. 2010). Many 
studies have demonstrated that conventional agricultural practices can significantly impact microbial communities in soil ecosystems (Villanueva-Rey et al. 2014; Hartmann et al. 2015). Although the grapevine is an important crop worldwide and preserving the biological quality of soil is mandatory for sustainable agriculture, knowledge about soil microbiological processes in vineyards is generally limited (Probst et al. 2008).

The addition of organic substances is of vital importance for soil quality and health (Baldi et al. 2010). Organic fertilizers can be a good solution for maintaining soil health, since the release of nutrients in soil is slower than for chemical fertilizers and often better matches plant needs in the growing season. Of the different organic fertilizers, green manure consists of growing specific crops in the inter-rows of the vineyard and then ploughing them into the terrain to improve soil quality. Green manure crops usually include grass mixtures and legume plants, such as vetch, clover, barley and others. Multiple benefits are produced by green manure. The physical structure of soil is improved, because green manure tends to reduce soil erosion and leaching (Ingels et al. 2005). This practice can also help to provide ecological niches supporting predators/parasitoids, improving pest control in the vineyard (Irvin et al. 2014). Green manure influences the grapevine plant and its fruit by enhancing the organoleptic characteristics of the grapes (Rotaru et al. 2011). Moreover, the organic carbon available for soil micro-organisms is significantly increased by green manure, which also enhances the activity of numerous soil enzymes, especially those involved in the $\mathrm{N}$ cycle (Okur et al. 2016). Although the advantages of using green manure have been recognized, little is known about the possible modifications that it could cause in soil microbial communities.

Organic agriculture is codified by the Council of the European Union (EC 834/2007) as a management that uses living organisms and mechanical production methods; excludes the use of genetically modified organisms (GMO) and the products derived from them; reduces the external inputs, that are limited to natural or naturally derived substances; and bans the use of chemically synthesized inputs. Biodynamic agriculture can be regarded as a pioneer version of organic agriculture (Kirchmann 1994), and it is currently a certification and labelling system included in the organic production. The principles of biodynamic agriculture were established in Germany by Rudolf Steiner in the 1920s. It adopts a holistic approach to the exploitation of natural resources, taking into consideration the sustainability of different elements, such as the crops themselves, animal life preservation or the maintenance of high-quality soil, in order to recover, preserve or improve ecological harmony. The biodynamic approach in farm practices reflects the metaphysical concepts proposed by its founder. It uses a set of specific compost preparations to be applied to crops to aid fertilization and the application of other homoeopathic treatments based on infusions or plant extracts (Lotter 2003), whose effect did not received scientific validation so far (Chalker-Scott 2013). For example, preparations 500 and 501 consist in cow manure and quartz powder, respectively, placed in a cow horn and buried, and then used in the field after a period of maturation.

Knowledge of how soil management affects soil microbial species richness and abundance is important because microbial diversity and stability determine the soil's ability to react to external changes, the impact and degradation (Munoz et al. 2007). Beneficial microbial processes are essential for crop production as they determine the soil's ability to supply nutrients to the plant; they retain nutrients in the profile, contribute to the formation of soil structure, suppress plant pathogens and contribute to soil humus formation (Ingels et al. 2005).

The main goal of this study was to investigate the effects of biodynamic viticulture on the microbial community structure and diversity of vineyard soils, with or without the addition of green manure, using high throughput sequencing, in comparison to organic management.

\section{Materials and methods}

\section{Sampling site and vineyard management}

The study site was located at an experimental site (1.0 ha) in the Trentino-South Tyrol region in northern Italy (San Michele all'Adige, $46 \cdot 19 \mathrm{~N}, 11 \cdot 14 \mathrm{E}$ ). The experiment was repeated in two vineyards, according a "split plot" design, with the vineyards (Field 1 and Field 2) as first factor and vineyard management (organic $(\mathrm{O})$, biodynamic (BD) or biodynamic with green manure (BDGM)) as second factor, starting from the autumn of 2011. The vineyards were both planted with Cabernet franc variety (clones 214, 331 and 327) on SO4 rootstock in 2002, and the Guyot vine training system was adopted $(2.0 \mathrm{~m} \times 1.0 \mathrm{~m})$. In the $\mathrm{O}$ plots, pneumatic leaf removal and mechanical hedging were adopted for canopy management, while in the BD and BDGM plots, pneumatic leaf removal was substituted with manual removal of lateral shoots, and instead of hedging, the shoots were rolled onto the last couple of wires in the vegetative wall. Chemical fertilizers were not applied to any of the plots, while all plots were treated with copper $\left(4.6 \mathrm{~kg} \mathrm{ha}^{-1}\right)$ and sulphur $\left(43 \mathrm{~kg} \mathrm{ha}^{-1}\right)$ to control fungal disease. In the $\mathrm{BD}$ and BDGM plots, biodynamic preparations 500 $\left(100 \mathrm{~g} \mathrm{ha}^{-1}\right)$ and $501\left(4 \mathrm{~g} \mathrm{ha}^{-1}\right)$ were used to stimulate 
humus formation, while no fertilizers were applied in the O. The inter-rows in the BDGM plots were sown with cover crops seed mixture for green manure $\left(181 \mathrm{Kg} \mathrm{ha}^{-1}\right.$, Table 1) on 5 October 2011, to limit physical degradation by compaction and dissolution. Green manure plants (dry weight of $0.58 \mathrm{Kg} \mathrm{m}^{-2}$ ) were mown on 15 May 2012 and incorporated into the soil. Specifically, in the BDGM plots, a chisel plough set at $50 \mathrm{~cm}$ was used before cover crop seeding, followed by a rotating harrow. Mechanical weed control was performed during inter row mowing in all the plots.

\section{Soil sampling and processing}

Soil sampling was carried out on 2 October 2012. Three sampling points were chosen along two grapevine rows (at the two ends and a central point) in each field and for each type of vineyard management. A total of 36 samples $(3$ replicates $\times 2$ rows $\times 2$ fields $\times 3$ vineyard managements) were collected.

For each sampling point, three-soil cores $(\varnothing 5 \mathrm{~cm}$, depth $19 \mathrm{~cm}$ ) were collected from the topsoil and transferred into sterile bags, after removing the first $5 \mathrm{~cm}$ of the soil layer (mostly humus). The soil samples were sieved separately to a $<2-\mathrm{mm}$ particle size, and an equal amount of soil from each sampling point was transferred into a 50-ml sterile falcon tube (Sarstedt, Germany), lyophilized and stored at $-80^{\circ} \mathrm{C}$ for metagenomic analysis.

Physical and chemical analysis was carried out on the remaining soil, after pooling by field, vineyard management and row $(n=12)$. The analyses were carried out following the official methods for soil chemical analysis (DM 11/05/92 and DM 13/09/99). The following parameters were measured: total sand $(2 \cdot 0-0 \cdot 050 \mathrm{~mm})$, silt $(0.050-0.002 \mathrm{~mm})$ and clay $(<0.002 \mathrm{~mm})$ were determined by measuring the volumetric mass of the watersoil suspension and the distribution of the elementary particles by wet sieving and hydrometer; total soil organic matter (SOM) and total nitrogen content $(\mathrm{N})$ were determined by elemental analysis using the Dumas method; carbon/nitrogen $(\mathrm{C} / \mathrm{N})$ ratio, calculated from total $\mathrm{C}$ and

Table 1 Composition of the cover crop seed mixture sown on 5 October 2011 for green manure and average productivity of the cover crops and natural grass measured on 15 May 2012 as dry weight

\begin{tabular}{ll}
\hline Cover crops & $\%$ Weight \\
\hline Vicia sativa & $11 \cdot 0$ \\
Pisum sativum & $22 \cdot 1$ \\
Vicia faba & $55 \cdot 2$ \\
Secale cereale & $11 \cdot 1$ \\
Brassica napus & $0 \cdot 6$ \\
\hline
\end{tabular}

$\mathrm{N}$. The $\mathrm{pH}$ was measured in 1:2.5 soil:water suspension; total $\mathrm{CaCO}_{3}$ by gas-volumetric determination of $\mathrm{CO}_{2}$ after $\mathrm{HCl}$ treatment (ISO 10693) and active limestone using the Drouineau method; $\mathrm{Mg}, \mathrm{K}$, exchangeable cations by extraction with ammonium acetate $1 \mathrm{M}$ at $\mathrm{pH}$ 7; $\mathrm{P}$ using the Olsen method; total $\mathrm{Cu}, \mathrm{Fe}, \mathrm{Mn}, \mathrm{Zn}, \mathrm{Pb}$ and $\mathrm{Cd}$ were quantified in aqua regia.

\section{DNA extraction, amplification and pyrosequencing}

Total genomic DNA was extracted from $0.5 \mathrm{~g}$ of lyophilized soil using a FastDNA ${ }^{\circledR}$ Spin kit (MP Biomedicals, France), following the manufacturer's instructions, and quantified using a NanoDrop 8000 spectrophotometer. For bacterial identification, the V1-V3 hypervariable region of $16 \mathrm{~S}$ rRNA was PCR amplified using the primer set 27f (Weisburg et al. 1991) and 518r (Muyzer et al. 1993). At the $5^{\prime}$ end, the forward primer carried the 454adaptor A with a specific Roche-10 nt multiplex identifier (MID) for each soil sample. Each sample was amplified in triplicate in a $25 \mu \mathrm{l}$ reaction, following the amplification protocol by Nicola et al. (2017). The $18 \mathrm{~S}$ rRNA-5.8S rRNA internal spacer (ITS) of fungal rRNA was amplified using the primer pair ITS1F (Gardes and Bruns 1993)ITS2 (White et al., 1990). One-way amplicon sequencing was carried out as in Nicola et al. (2017). Three independent PCR reactions (technical replicates) were performed for each sample and pooled together. All the PCR products were then analysed with gel electrophoresis and cleaned using an AMPure XP beads kit (Beckman Coulter, Brea, CA). Two final and distinct libraries (16S and ITS) were constructed from the 36 PCR products. Pyrosequencing was performed on a GS FLX+ system (Roche, Mannheim, Germany) using XL+chemistry, following the manufacturer's instructions.

\section{$16 \mathrm{~S}$ rRNA gene and ITS sequence processing}

Pyrosequence quality was checked in PRINSEQ (Schmieder and Edwards 2011) and flowgrams were filtered and denoised using FlowClus (Gaspar and Thomas 2015). Denoised microbial reads were processed using Metaxa2 v2 $1 \cdot 3$ (Bengtsson-Palme et al. 2015) to target the extraction and to verify the $16 \mathrm{~S}$ rRNA variable regions. Similarly, but for fungal reads, ITSx v1·0·11 (Bengtsson-Palme et al. 2013) was used to target the ITS1. USEARCH v7 (Edgar 2013) was used to de-replicate, sort and cluster the extracted regions with $97 \%$ pairwise sequence identity. Chimeras were removed by adopting both de novo and reference based methods as features of the abovementioned tool. The RDP classifier train set n.15 (2015/ 09) was used as a reference database for microbial chimeras, whereas the UNITE reference sequences version $n$. 
$7 \cdot 0(2016 / 01)$ were chosen for fungal ITS chimera detection in UCHIME (Edgar et al. 2011). Taxonomy assignment was performed by employing naive Bayesian RDP classifier v2.10 (Wang et al. 2007) in QIIME (Caporaso et al. 2010) with a minimum confidence of 0.6 against the SILVA database, release 123 (2016/05) (Quast et al. 2013) and the UNITE database, version n. 7·1 (2016/08) (Abarenkov et al. 2010) for 16S rRNA-based and ITSbased sequences, respectively. Sequence data were made available in the NCBI SRA database under BioProject number PRJNA381189.

\section{S rRNA gene-based microbial and ITS-based fungal community analysis and statistics}

OTU-based analysis was carried out in QIIME to calculate richness and diversity after multiple rarefaction (5 870 and 2348 read depth for bacteria and fungi, respectively). The OTUs observed were counted and the diversity within each individual sample was estimated using Simpson's diversity index. Richness and diversity values were separately analysed in $\mathrm{R}$, fitting all the factors in generalized linear models (GLMs) assuming a Gamma distribution and validated via graphical representation of residuals vs. fitted values. The statistical significance of the GLMs was inferred by adopting the chi-square test, and post hoc pairwise comparisons were calculated using Tukey's HSD test in the multcomp R package (Hothorn et al. 2008). Microbial and fungal richness and diversity values were graphically represented as box plots using the ggplot2 $\mathrm{R}$ package.

Multivariate analysis of community structure and diversity was performed according to the recommendations of Anderson and Willis (2003): (i) unconstrained ordination offered by Principal Coordinate Analysis (PCoA) (data not shown); (ii) constrained multidimensional scaling using Constrained Analysis of Principal Coordinates (CAP) as re-implemented in the vegan $\mathrm{R}$ package (Oksanen et al. 2017); (iii) permutation test to assess the significance of the constraints and permutational multivariate analysis of variance (PERMANOVA); (iv) identification and correlation of OTUs responsible for shaping the diversity structure. The effects of rare species were downweighted by applying Hellinger transformation to the rarefied OTU tables.

In more detail, the differences between bacterial communities were investigated using the Bray-Curtis dissimilarity distance and the ordination methods applied to the same distance matrices. All the ordination analyses were computed and CAP plotted in phyloseq (points 1 and 2). The significance of the treatment grouping factor used as a constraint in CAP was assessed via the permutation test in the vegan $\mathrm{R}$ package. The null hypothesis of no differences between a priori defined groups was investigated using the PERMANOVA approach, implemented in vegan as the ADONIS function and applied to the BrayCurtis dissimilarity distances.

Permutational pairwise comparisons between the treatments were carried out with the RVAideMemoire R package (Hervé 2017) and P-values were FDR-adjusted (point 3 ). Indicator OTU analysis was applied for calculation of differential OTU abundance in treatments using the indicspecies R package (De Caceres and Legendre 2009) and $P$-values were FDR-adjusted. Procrustes analysis (Lisboa et al. 2014) was then applied to CAP ordinations to correlate bacterial and fungal beta-diversity in response to different farming practices (point 4). Differential OTU abundance for treatments at genus level was assessed via permutation ANOVA (RVAideMemoire $\mathrm{R}$ package) for both the bacterial and fungal dataset. Significantly different genera (FDR-adjusted $P$-values) were then shown as bar plots (mean $\pm \mathrm{SD}$ of number of reads), and for each genus, the pairwise permutation $t$-test was applied to all treatment combinations.

\section{Results}

The physical and chemical analysis of soil (Table 2) did not reveal statistically significant differences between the types of management.

Pyrosequencing yielded a total of 401824 raw pyrotags reads for bacteria and 305990 reads for fungi. After quality filtering and chimera removal, a total of $31491016 \mathrm{~S}$ rRNA sequences and 164227 ITS sequences remained for community analysis, corresponding to an average \pm SD of $8997 \pm 1726$ reads and $4562 \pm 1367$ reads per sample for bacteria and fungi, respectively. A total of 4809 bacterial OTUs and 633 fungal OTUs were detected (Figs. S1 and S2).

The most abundant bacterial phyla, in all soil samples, were Actinobacteria (31.71\%), Proteobacteria (21.96\%), Acidobacteria (12.78\%) and Gemmatimonadetes (8.29\%). A total of 32 phyla, 116 classes, 255 orders, 505 families and 850 genera were detected. As regards genera, the most abundant in vineyard soil were Gaiella sp. (5.66\%), Bacillus sp. (1.99\%), Arthrobacter sp. (1.74\%) and Nitrospira sp. (1.26\%) for bacteria. The fungal communities were instead dominated by Ascomycota (77\%), Basidiomycota (16\%) and Zygomycota (7\%). Overall, a total of six phyla, 22 classes, 61 orders, 124 families and 220 genera were found in the soil samples. The Ascomycota mostly consisted of Sordariomycetes, followed in decreasing order of relative abundance by Dothideomycetes and Eurotiomycetes. More than 37\% of the Sordariomycetes reads belonged to the Hypocreales order, and within this order Nectriaceae were the most abundant family. 
Table 2 Physical-chemical analysis of soil samples, divided according to the management system applied (average \pm SD). O, samples from organically managed soil; BD, samples from biodynamically managed soil; BDGM, samples from biodynamically managed soil with the addition of green manure as fertilizer

\begin{tabular}{|c|c|c|c|}
\hline Parameter & O & $\mathrm{BD}$ & BDGM \\
\hline $\mathrm{pH}$ & $7.97 \pm 0.02$ & $7.97 \pm 0.01$ & $7.97 \pm 0.09$ \\
\hline Total limestone $\left(\mathrm{g} \mathrm{kg}^{-1} \mathrm{CaCO}_{3}\right)$ & $367.50 \pm 9.19$ & $365 \cdot 50 \pm 6.36$ & $371.00 \pm 1.41$ \\
\hline Active limestone $\left(\mathrm{g} \mathrm{kg}^{-1}\right)$ & $13.50 \pm 0.71$ & $13.00 \pm 0.00$ & $12.50 \pm 0.71$ \\
\hline Organic substance $\left(\mathrm{g} \mathrm{kg}^{-1}\right)$ & $24.00 \pm 1.41$ & $22 \cdot 50 \pm 2 \cdot 12$ & $26.00 \pm 8.49$ \\
\hline$N\left(\mathrm{~g} \mathrm{~kg}^{-1}\right)$ & $1.10 \pm 0.00$ & $1.10 \pm 0.00$ & $1.40 \pm 0.42$ \\
\hline $\mathrm{C} / \mathrm{N}$ & $12.51 \pm 0.83$ & $11.82 \pm 0.75$ & $11.00 \pm 0.01$ \\
\hline $\mathrm{P}_{2} \mathrm{O} 5\left(\mathrm{mg} \mathrm{kg}^{-1}\right)$ & $59.50 \pm 0.71$ & $54.00 \pm 11.31$ & $61.00 \pm 21.21$ \\
\hline $\mathrm{K}_{2} \mathrm{O}\left(\mathrm{mg} \mathrm{kg}^{-1}\right)$ & $229.00 \pm 15.56$ & $233.00 \pm 2.83$ & $214.00 \pm 21.21$ \\
\hline $\mathrm{MgO}\left(\mathrm{mg} \mathrm{kg}^{-1}\right)$ & $417.00 \pm 43.84$ & $446.00 \pm 0.00$ & $466.50 \pm 57.28$ \\
\hline CSC (meq per $100 \mathrm{~g}$ ) & $14.40 \pm 0.71$ & $15.05 \pm 0.92$ & $15.80 \pm 1.84$ \\
\hline Cu DTPA (mg kg $\left.{ }^{-1}\right)$ & $27.65 \pm 4.31$ & $27.90 \pm 7.35$ & $32.85 \pm 14.50$ \\
\hline Fe DTPA $\left(\mathrm{mg} \mathrm{kg}^{-1}\right)$ & $10 \cdot 70 \pm 0.00$ & $11.13 \pm 1.80$ & $11.00 \pm 0.71$ \\
\hline Mn DTPA $\left(\mathrm{mg} \mathrm{kg}^{-1}\right)$ & $10.85 \pm 1.06$ & $10 \cdot 13 \pm 0.66$ & $11.05 \pm 1.34$ \\
\hline Zn DTPA (mg kg $\left.{ }^{-1}\right)$ & $4.65 \pm 0.72$ & $4.89 \pm 1.04$ & $5.71 \pm 2.57$ \\
\hline Pb DTPA $\left(\mathrm{mg} \mathrm{kg}^{-1}\right)$ & $21.42 \pm 2.81$ & $26 \cdot 48 \pm 10 \cdot 77$ & $23.45 \pm 7.12$ \\
\hline Cd DTPA (mg kg $\left.{ }^{-1}\right)$ & $0.10 \pm 0.00$ & $0.10 \pm 0.01$ & $0.10 \pm 0.01$ \\
\hline Sand $\left(\mathrm{g} \mathrm{kg}^{-1}\right)$ & $295.50 \pm 7.78$ & $263.50 \pm 12.02$ & $285.00 \pm 9.90$ \\
\hline Silt $\left(\mathrm{g} \mathrm{kg}^{-1}\right)$ & $534.50 \pm 6.36$ & $556 \cdot 50 \pm 26 \cdot 16$ & $550.00 \pm 11.31$ \\
\hline Clay $\left(\mathrm{g} \mathrm{kg}^{-1}\right)$ & $170.00 \pm 14.14$ & $180.00 \pm 14.14$ & $165.00 \pm 21.21$ \\
\hline
\end{tabular}

Clonostachys sp. (13.29\%), Coprinellus sp. (8.13\%), Exophiala sp. $(4 \cdot 15 \%)$ and Fusarium sp. $(4 \cdot 08 \%)$ were the most abundant genera of fungi.

The Glomeromycota phylum, an important soil microbial group that forms one of the most common types of symbiosis (arbuscular mycorrhizal fungi; AMF), presented a low abundance $(0 \cdot 19 \%)$ in all soils and the management systems did not influence its diversity. Three classes -Archaeosporales, Glomerales and Paraglomerales-represented this phylum. The Glomeraceae family was more abundant compared with the Ambisporaceae and Paraglomeraceae families. The Glomus and Funneliformis genera were common with all the management systems, while the genus Septoglomus was present in $\mathrm{O}$ and BD soils and was almost absent in BDGM soils.

The alpha (within-sample) diversity (observed OTUs) found in bacterial communities in biodynamic soils with green manure (BDGM) was significantly higher than that in organic $(\mathrm{O})$ and biodynamic (BD) soils (Fig. 1a; Table S1). Moreover, the bacterial richness in Field 1 was significantly greater than in Field 2, and the same trend was observed in fungal communities (Fig. 1b). However, the different types of soil management did not influence fungal alpha-diversity. When looking at Simpson's diversity values, no significant differences were found between grouping factors $(P>0 \cdot 05)$.

When beta (between-sample) diversity was analysed using PERMANOVA, both fungal and bacterial communities were significantly different according to the type of soil management, the field of origin and the interaction between the two $(P<0.001$, Table S2). With permutational pairwise comparisons, it was ascertained that the microbiome of BDGM soils was significantly different from those in $\mathrm{O}$ and $\mathrm{BD}$ soils $(P=0.045, P=0.019$, respectively). Building on these results, constrained analysis of principal coordinates (CAP) was performed on bacteria and fungi (Fig. 2), using the factors that appeared to be significant in PERMANOVA as constraints. The samples were divided according to the type of soil management (BDGM vs $\mathrm{O}$ and $\mathrm{BD}$ ) and the field of origin, both for bacteria and fungi. Procrustes correlation testing for CAP analysis was performed and a correlation of 0.51 $(\mathrm{m} 12=0.74)$ with a significance $P<0.001$ was found, meaning that bacterial and fungal diversity reacted in a similar way to soil management. Bacterial and fungal indicator OTUs significant for soil management were identified. In BDGM and BD soils, the bacterial indicator species were mainly genera associated with the soil nitrogen cycle, such as Nitrospira sp., Pontibacter sp. and Frankia sp. (Table 3). The fungal indicator species were instead mainly saprobic fungi in each type of soil management (Table 4). Exophiala sp., a black yeast often associated with soil enriched with organic waste, was the indicator species in $\mathrm{O}$ soils. In BD soils, Mortierella sp., Mortierella Antarctica, Humicola nigrescens and the antagonistic fungus Acremonium persicinum were the indicator OTUs. However, BDGM soils contained the biocontrol agent and plant growth promoting Cladorrhinum sp., 

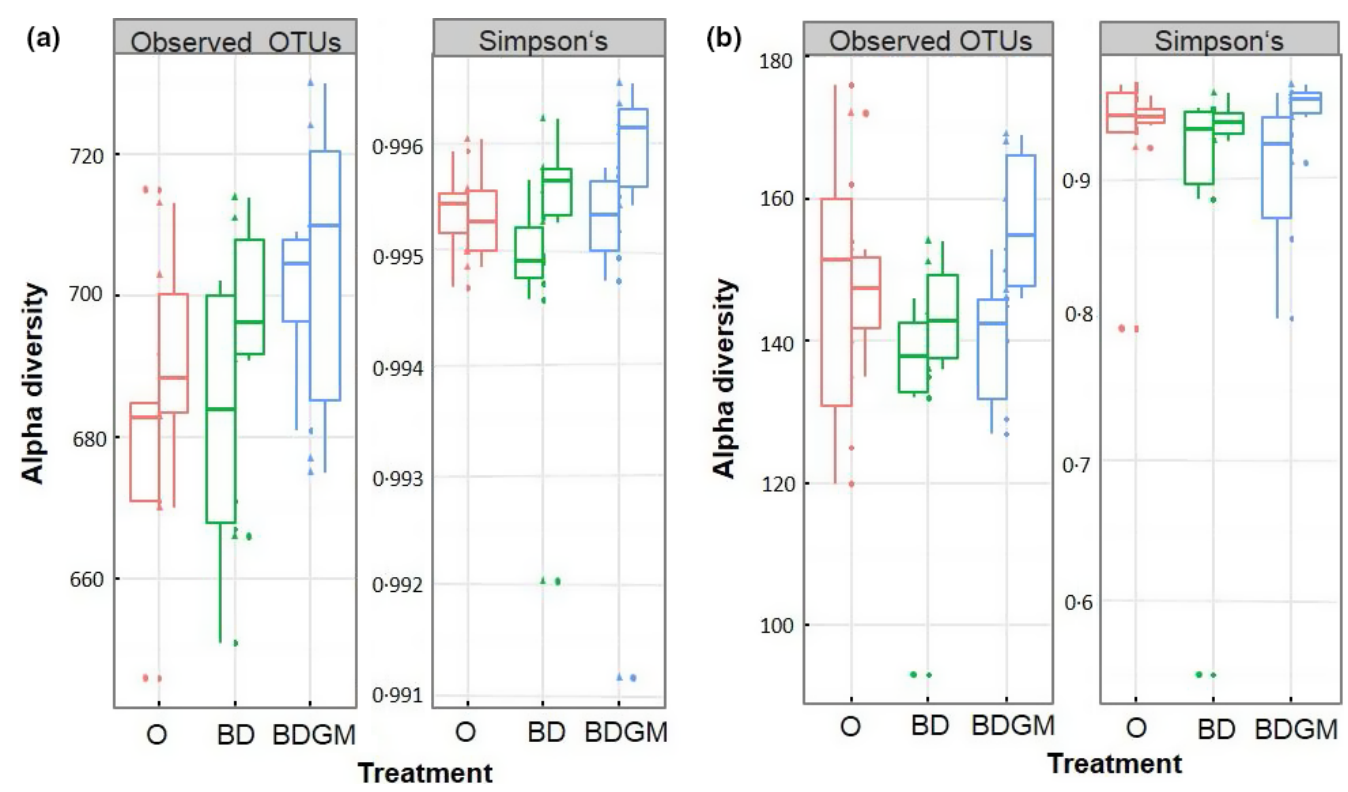

Figure 1 Box plots representing observed OTUs and Simpson indices of bacterial (a) and fungal (b) communities in vineyard soils managed with different sustainable approaches. O, samples from organically managed soil; BD, samples from biodynamically managed soil; BDGM, samples from biodynamically managed soil with the addition of green manure; $(\bullet)$ soil samples from Field $1 ;(\boldsymbol{\Lambda})$ soil samples from Field 2 . [Colour figure can be viewed at wileyonlinelibrary.com]
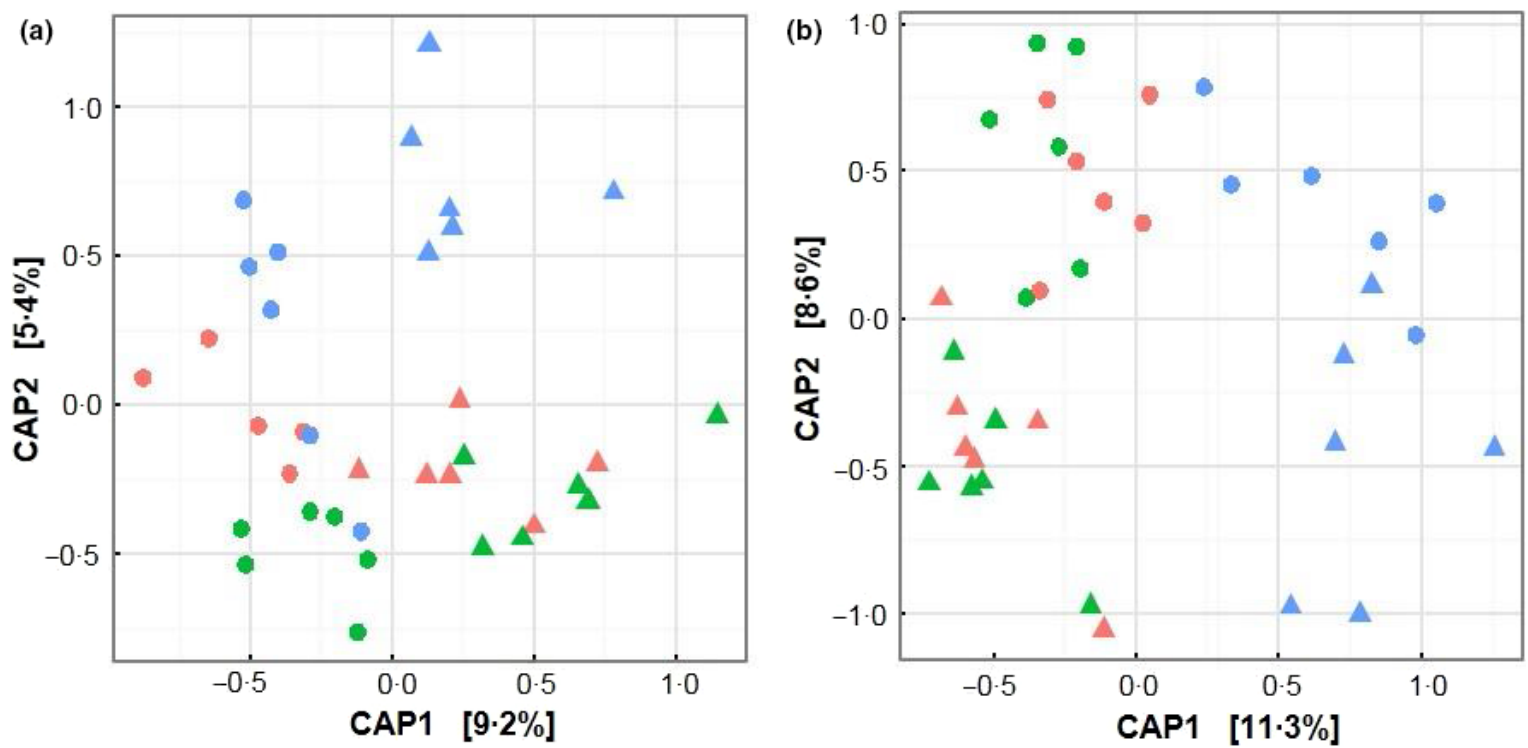

Figure 2 Constrained analysis of principal coordinates (CAP), based on the Bray-Curtis dissimilarity distance of 454 sequencing bacterial (a) and fungal (b) data for soil samples from vineyard soils managed with different sustainable approaches. O, samples from organically managed soil; $B D$, samples from biodynamically managed soil; BDGM, samples from biodynamically managed soil with the addition of green manure; $(\mathbf{})$ soil samples from Field 1, ( $\mathbf{\Lambda})$ soil samples from Field 2. [Colour figure can be viewed at wileyonlinelibrary.com]

Capnobotryella sp., a black-pigmented fungi, Cystofilobasidium capitatum, a pectinolytic yeast and Exophiala sp.

As regards the differences in OTU abundance in O soil and $\mathrm{BD}$ and BDGM soil, calculated by permutation ANOVA, we found two nitrogen-fixing bacterial genera
(Microvirga sp. and Pontibacter sp.) to be significantly more abundant in BDGM soils, together with Actinoplanes sp., which has an important role both in the degradation of fallen leaves and as an antagonist of oomycetes like Pythium and Phytophthora (Fig. 3, 
Table 3 Bacterial indicator OTUs for the different types of vineyard soil management obtained with the indicspecies R package ( $P$-values corrected using FDR). $\mathrm{O}$, samples from organically managed soil; BDGM, samples from biodynamically managed soil with the addition of green manure as fertilizer

\begin{tabular}{lll}
\hline Soil management & Bacterial OTUs & $P$-values \\
\hline O & Lactobacillus sp. & 0.0496 \\
BDGM & Nitrospira sp. & 0.0037 \\
& Catelliglobosispora sp. & 0.0037 \\
& Planosporangium sp. & 0.0396 \\
& Paenibacillus sp. & 0.0496 \\
& Pontibacter sp. & 0.0496 \\
\hline
\end{tabular}

Table 4 Fungal indicator OTUs for the different types of vineyard soil management obtained with the indicspecies $\mathrm{R}$ package ( $P$-values corrected using FDR). $\mathrm{O}$, samples from organically managed soil; $B D$, samples from biodynamically managed soil; BDGM, samples from biodynamically managed soil with the addition of green manure as fertilizer

\begin{tabular}{lll}
\hline Soil management & Fungal OTUs & $P$-values \\
\hline O & Exophiala sp. 1 & 0.0440 \\
BD & Mortierella antarctica & 0.0069 \\
& Acremonium persicinum & 0.0092 \\
& Mortierella sp. 04M 158 & 0.0069 \\
BDGM & Humicola nigrescens & 0.0166 \\
& Exophiala sp. 2 & 0.0104 \\
& Capnobotryella sp. MA 4775 & 0.0173 \\
& Cystofilobasidium capitatum & 0.0270 \\
& Cladorrhinum sp. & 0.0303 \\
\hline
\end{tabular}

Table S3). However, the genus Terrimonas, involved in S cycling in soil, was significantly more abundant in $\mathrm{O}$ soil than in BD and BDGM soil. In fungal analysis, the genera Cladorrhinum, Cystofilobasidium and Myrmecridium and the psychrophilic basidiomycetous yeast Mrakiella sp. were significantly more abundant in BDGM soils (Fig. 4, Table S4). In addition, the genera Colletotrichum, Gibberella and Leptosphaeria, which include pathogenic species of plants, were abundant where green manure was applied. In contrast, Clonostachys sp. and Pyrenochaeta sp., associated with biocontrol and plant pathogens respectively, were more abundant in $\mathrm{O}$ and $\mathrm{BD}$ samples than in BDGM samples.

\section{Discussion}

Scientific studies on biodynamic management in vineyards and its effect on soil microbiota are rare (Burns et al. 2016), since most works tend to concentrate on the effects on plants or grapes. Recent work on biodynamic viticulture has affirmed that in terms of grape health, the microbiological and chemical characteristics in these vineyards were comparable or better to those in vineyards cultivated using conventional methods (Guzzon et al. 2016).

There are several theories regarding the way in which the biodynamic preparations may interact with crops and may include hormonal stimulation, enhancing crop growth, especially at root level (Villanueva-Rey et al. 2014). As regards the effects of biodynamic preparations, according to Chalker-Scott (2013), the addition of these products did not affect the yield of the crops analysed, and other authors have also stated that biodynamic preparations had little influence on plant biotic parameters (Doring et al. 2015; Baskar and Shanmugham 2016).

We used the high-resolution power of 454-pyrosequencing to investigate soil microbial biodiversity in sustainably managed vineyards, specifically studying the shortterm effects of two types of farming management ( $\mathrm{O}$, $\mathrm{BD})$ and green manure application (BD, BDGM) on the diversity, richness and composition of soil microbial communities. In our study, no difference in alpha or beta diversity was noticed between $\mathrm{O}$ and $\mathrm{BD}$ soil samples. This is in agreement with previous studies on biodynamic management, which have indicated similar behaviour for organic and biodynamic farming systems in terms of microbial soil composition and diversity. In fact, Carpenter-Boggs et al. (2000) found that organically and biodynamically managed soils had a similar microbial composition, but they were more biotically active than soils that did not receive organic fertilization. Moreover, organic management enhanced soil biological activity, but additional use of biodynamic preparations did not significantly affect the soil biotic parameters tested. In this study, we have to consider the short-term exposure of the soil microbiota to the different vineyard managements. According to Hartmann et al. (2015), the shortterm effect of agricultural management has shown a fewer impact than the long-term effects, mainly on bacterial community and the spatiotemporal variability was important to reveal the shift of the structure of the soil microbiota.

Green manure application had a major impact on soil micro-organisms. Our results showed the crucial importance of green manure for soil microbiota, since it promoted higher bacterial richness and significant changes in the microbial communities found in BDGM soils. Bacteria and fungi responded in a similar way to green manure application. These results are in accordance with Ingels et al. (2005), who analysed microbial communities using phospholipid fatty acid (PLFA) analysis, showing that biodynamic management associated with green manure application increased the taxonomic and phylogenetic richness, diversity and heterogeneity of soil microbiota compared with other farming systems. Furthermore, 

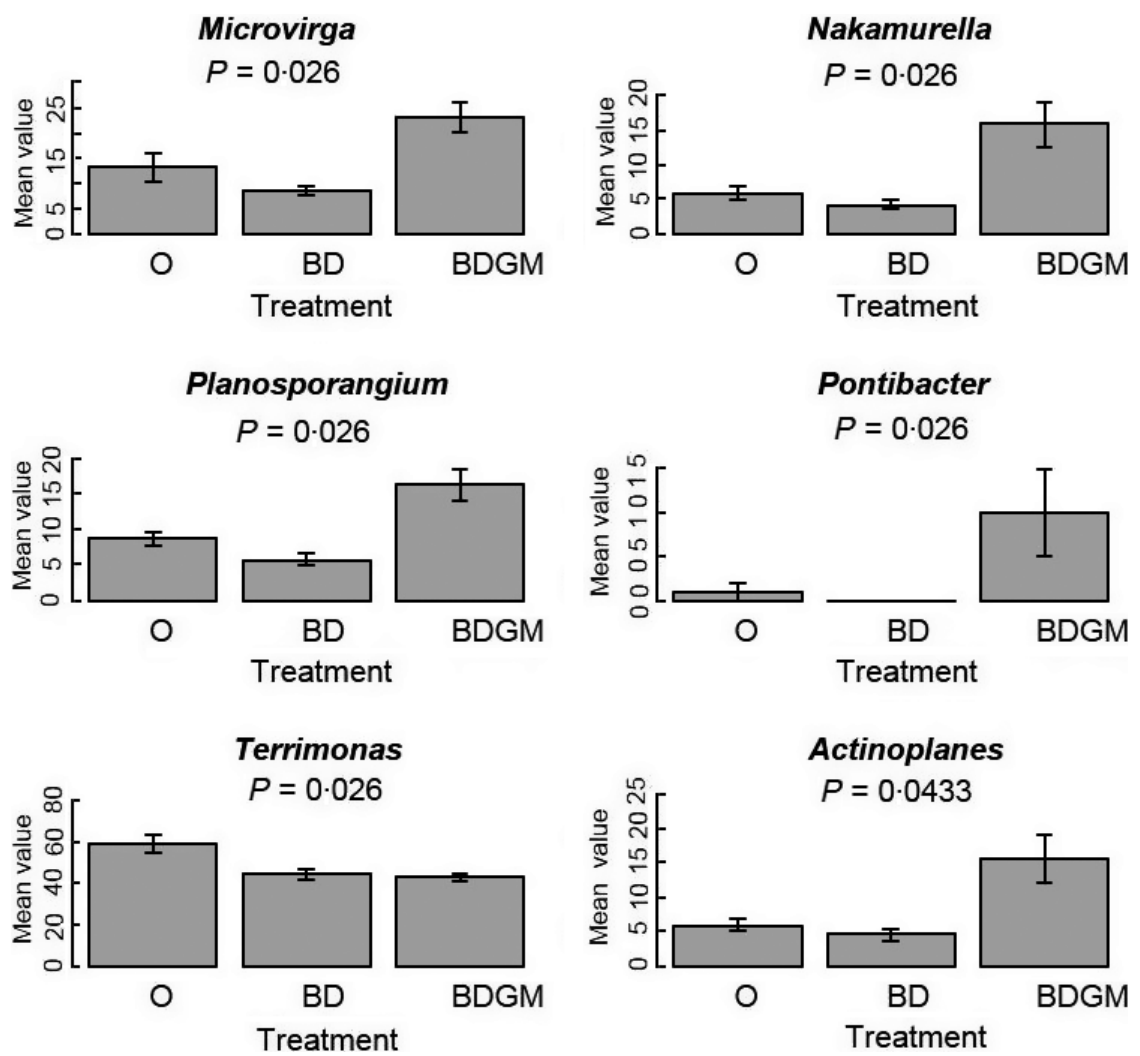

Figure 3 Bar plots of the different bacterial OTU abundance at genus level for different types of vineyard soil management obtained via permutation ANOVA. Only significantly different genera ( $P$-values corrected using FDR) are shown (mean \pm SD of number of reads). 0 , samples from organically managed soil, BD, samples from biodynamically managed soil, BDGM, samples from biodynamically managed soil with the addition of green manure.

Wittwer et al. (2017) highlighted other benefits of cover crops, such as providing various ecological services to agro-ecosystems, protection against soil erosion, reduction of nutrient losses, improvement of soil and water quality, and to some extent, a reduction in weeds and pests.

Moreover, the addition of green manure significantly enriched the population of bacteria potentially active in the soil nutrient cycle, such as Microvirga sp., Pontibacter sp. and Actinoplanes sp. Microvirga sp. is a nitrogen-fixing bacterium that is often found in symbiosis in the root nodules of legumes (Ardley et al. 2012; Reeve et al. 2014). Pontibacter sp. is a Gram-negative genus isolated from different environments, such as different kinds of soil, muddy water and marine water (Srinivasan et al. 2014), and some strains carry out nitrogen-fixing activity in soil (Xu et al. 2014). However, Actinoplanes sp. is often found in leaf litter (Nurkanto et al. 2016) and may have an important role in the degradation of fallen leaves and organic matter (Hop et al. 2011), in addition to exercising antagonistic activities against several soil-borne pathogens, such as Pythium spp. and Phytophthora megasperma (Filonow and Lockwood 1985; El-Tarabily et al. 2010). Green manure also increased the presence of some fungal OTUs, such as the genus Cladorrhinum, a fungal group of prime importance for agriculture and livestock, since some species have biocontrol potential or have been shown to promote plant growth and produce phytases (Carmaran et al. 2015), and the cold-adapted heterobasidiomycetous genus Cystofilobasidium, which can utilize D-glucuronate and inositol as sole carbon sources and the assimilation of nitrate as sole nitrogen source (Linkind et al. 2009). Other increased fungal OTUs in BDGM were Myrmecridium, a fungal genus whose members are either saprobes or plant endophytes (Peintner et al. 2016) and the psychrophilic basidiomycetous yeast Mrakiella. The genera Colletotrichum, Gibberella and Leptosphaeria, which include important phytopathogens of many economically significant plants cultivated around the world, were also more abundant where green manure was applied.

As regards bacterial composition, the two most abundant bacterial phyla in these soil samples, Actinobacteria and Proteobacteria, are copiotrophs in soil, and they are 


\section{Camarosporium}

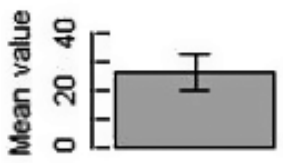

O<smiles>O=PO[Mg]</smiles>

BD

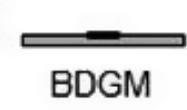

Treatment

Cystofilobasidium
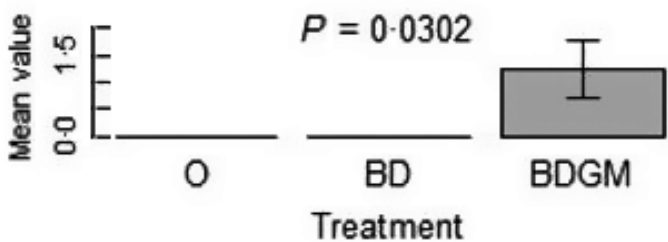

Mrakiella

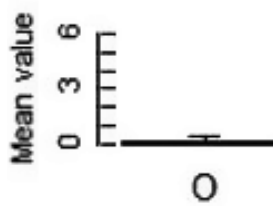

O

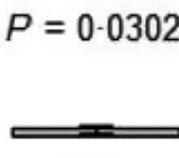

BD

Treatment

\section{Clonostachys}

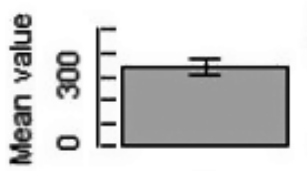

$\mathrm{O}$

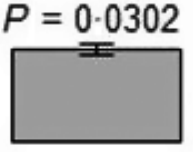

BD

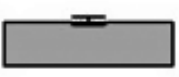

BDGM

Treatment

Pyrenochaeta

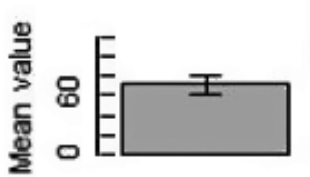

$\mathrm{O}$
$P=0.0403$

BD

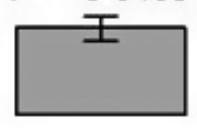

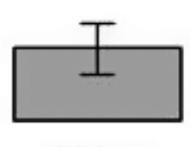

BDGM

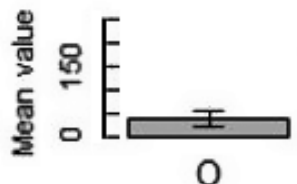

O

$\mathrm{O}$

BD $P=0.0302$

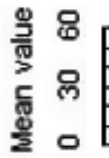

Treatment

Gibberella

$P=0.0302$

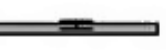

BD

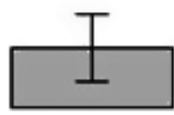

BDGM

Treatment

Myrmecridium

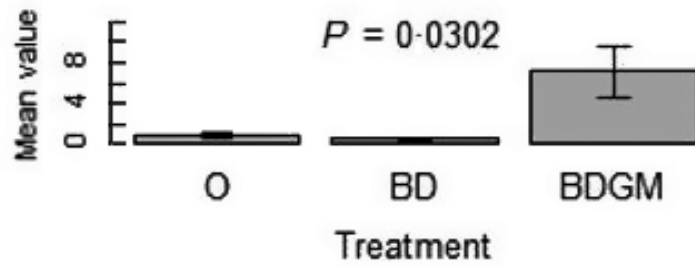

\section{Leptosphaeria}

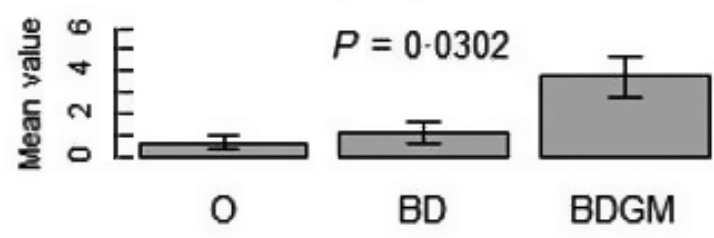

Colletotrichum

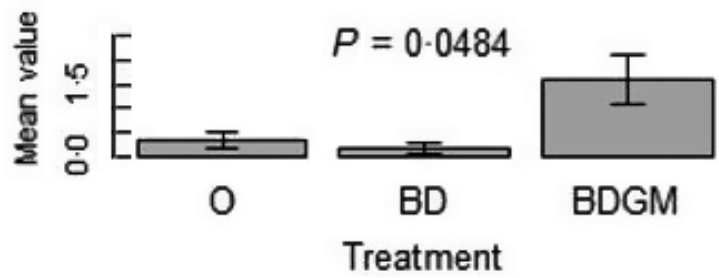

Figure 4 Bar plots of the different fungal OTU abundance at genus level for different types of vineyard soil management obtained via permutation ANOVA. Only significantly different genera ( $P$-values corrected using FDR) are shown (mean \pm SD of number of reads). $O$, samples from organically managed soil, BD, samples from biodynamically managed soil, BDGM, samples from biodynamically managed soil with the addition of green manure.

plentiful in conditions of high nutrient availability, exhibiting high growth rates (Fierer et al. 2007). The third phylum in order of abundance was Acidobacteria, which instead comprises oligotrophic soil bacteria (Fierer et al. 2007; Schimel and Schaeffer 2012). As regards fungi, OTUs belonging to the phylum Ascomycota were 
dominant in all types of soil management, which is common in cultivated soil (Sugiyama et al. 2010; FrankeWhittle et al. 2015; Abujabhah et al. 2016), and were followed by those of Basidiomycota, Zygomycota and Chytridiomycota. A similar trend was observed by Orgiazzi et al. (2012) when analysing ITS fragments from different soil types with 454 pyrosequencing.

In this work, almost all the microbial genera were found indiscriminately in each of the management systems at both sites. However, differences in abundance could be detected and some OTUs could be associated with specific types of soil management as their indicator OTUs. In O soils, only two indicator OTUs were found, the bacterium Lactobacillus sp. and the fungus Exophiala sp. Lactobacillus sp. often grows on grape skin (Bae et al. 2006; Nisiotou et al. 2015), but it can also be isolated from soil and it shows antifungal activity against several fungi, among which Fusarium spp. (Baffoni et al. 2015; Gajbhiye and Kapadnis 2016). According to Franke-Whittle et al. (2015), the genus Exophiala includes black yeasts that had negative correlations with apple plant growth and that were significant due to the high abundance in the soil. Black yeasts is a terminus technicus describing a heterogeneous group of fungi that have in common melanized cell walls and the formation of cells by yeast-like budding (Sterflinger 2006). While no bacteria were significantly associated with this treatment, four common saprotrophic soil fungi were indicator OTUs in BD soils. These were Mortierella sp. and Mortierella antarctica, which occur mainly in the soil of different ecosystems, including terrestrial habitats of Antarctica (Adams et al. 2006); Humicola nigrescens, a thermophilic mould capable of efficiently degrading organic materials by secreting thermostable enzymes (Singh et al. 2016); and Acremonium persicinum, an endophytic fungus of the grapevine with antagonistic activity against both the asexual and sexual spores of Plasmopara viticola (Burruano et al. 2016). Acremonium persicinum also hydrolyses cellulose and produces cephalosporin $\mathrm{C}$, which is a major precursor of semisynthetic cephalosporin antibiotics used to treat a wide range of bacterial infections (Sarookhani and Moazzami 2007).

As regards the bacterial indicator species of BDGM soils, there were three bacterial genera involved in the soil nitrogen cycle (Nitrospira sp., Paenibacillus sp. and the aforementioned nitrogen-fixing Pontibacter sp.). Nitrospira sp. belongs to nitrite-oxidizing bacteria (NOB) (Hayatsu et al. 2008) and is widely distributed in many habitats, including soil, oceans, freshwater and wastewater treatment plants (Koch et al. 2015). In soil, it is often associated with an increased supply of nitrogen from mineral fertilization (Zhou et al. 2015). Another nitrogen-fixing bacterium is Paenibacillus sp., which is also considered a plant growth promoter due to its production of IAA (indole-3-acetic acid), and it also has biocontrol potential against grapevine pathogens such as Botrytis cinerea and Neofusicoccum parvum (Grady et al. 2016; Haidar et al. 2016). As regards fungi, four black yeasts (Cladorrhinum sp., Capnobotryella sp., Cystofilobasidium capitatum and Exophiala) were fungal indicator OTUs in BDGM soils. Most of these genera are found as saprobes colonizing inert surfaces, or in hydrocarbon- or heavymetal-polluted habitats, and several are potential human pathogens (Seyedmousavi et al. 2014). Currently, little information about the ecophysiology of other detected indicator OTUs (Catelliglobosispora sp., Planosporangium sp. and Capnobotryella sp.) is available in order to deduce any putative ecological role in the soil system. Two different techniques that are commonly used to investigate the differences in microbial communities (indicator species and OTU identified by permutational ANOVA) detected different groups of OTUs. Both techniques individuated Planosporangium sp. and Pontibacter sp. as significant bacterial OTUs in BDGM soils, while no correspondences were found in fungal OTUs. These discrepancies in methods indicate how difficult can be a univocal characterization of microbial communities, since different valid statistical tools can give different answers, depending on the algorithms applied. For this reason, we decided to maintain and analyse both results, in exploiting two different techniques of analysis.

Arbuscular mycorrhizal fungi occur in the roots of most plants and are an ecologically important component of the soil microbiome. Analysis of the OTUs belonging to Glomeromycota showed a low level of AMF relative abundance. Also Hartmann et al. (2015) have observed only few Glomeromycota associated to different organic and conventional management systems using 454 pyrosequencing analysis. According to Orgiazzi et al. (2012), ectomycorrhizal phylotypes are numerous in natural sites covered by trees, but they are almost completely lacking in anthropogenic and grass-covered sites. Ciccolini et al. (2016), on studying the community of AMF with 454 pyrosequencing, reported a low level of AMF richness in intense cropping systems. However, we should also consider the limited coverage by the primers used in this work to be partly responsible for the few Glomeromycota observed (Stockinger et al. 2010). The genus Glomus was most abundant and present in all soils, in accordance with other studies, which have found this genus to be the most abundant AMF in the grapevine (Schreiner and Mihara 2009).

Soil is a nonrenewable resource and most vineyard soils are considered to be highly degraded in terms of loss of organic carbon, as a result of a decrease in nutrient content, an accumulation of metals and organic 
pollutants (Coll et al. 2011). The effect of agricultural management systems on soil micro-organisms is generally studied with plants undergoing rotation, but less is known about soils used for perennial plants, such as the grapevine. This is one of the few works comparing the microbial communities of soil in organic and biodynamic vineyards using 454 pyrosequencing. Overall, our results showed that the diversity and composition of the microbial communities associated with biodynamic and organic farming systems were similar, indicating that the use of biodynamic preparations 500 and 501 did not cause any significant detectable changes to the soil microbial community in the short term, while the effects of green manure were significant in soil microbiota. The increase in soil microbial diversity associated with the use of green manure could have possible benefits for plant nutrition, considering that in organic farming systems mineralization of organic matter depends on soil micro-organism activity. The incorporation of green manure was shown to increase the diversity of micro-organisms in soil, particularly the abundance of specific bacteria and fungi. Evidence of increased nitrogen-fixing and nitrite-oxidizing bacteria populations in soil as a response to the use of green manure suggests that they can potentially be adopted to increase nitrogen availability. An extension of organic/biodynamic farming associated with green manure application could contribute to maintaining higher microbial biodiversity in vineyard soil and consequently positively influence overall soil quality.

\section{Acknowledgements}

We acknowledge Vivienne Frankell for the English review of the manuscript.

\section{Conflict of Interest}

The authors declare that they have no competing interests.

\section{References}

Abarenkov, K., Nilsson, R.H., Larsson, K.H., Alexander, I.J., Eberhardt, U., Erland, S., Hoiland, K., Kjoller, R. et al. (2010) The UNITE database for molecular identification of fungi - Recent updates and future perspectives. New Phytol 186, 281-285.

Abujabhah, I.S., Bound, S.A., Doyle, R. and Bowman, J.P. (2016) Effects of biochar and compost amendments on soil physico-chemical properties and the total community within a temperate agricultural soil. Appl Soil Ecol 98, 243-253.

Adams, B.J., Bardgett, R.D., Ayres, E., Wall, D.H., Aislabie, J., Bamforth, S., Bargagli, R., Cary, C. et al. (2006) Diversity and distribution of Victoria Land biota. Soil Biol Biochem 38, 3003-3018.

Anderson, M.J. and Willis, T.J. (2003) Canonical analysis of principal coordinates: a useful method of constrained ordination for ecology. Ecology 84, 511-525.

Ardley, J.K., Parker, M.A., De Meyer, S.E., Trengove, R.D., O’Hara, G.W., Reeve, W.G., Yates, R.J., Dilworth, M.J. et al. (2012) Microvirga lupini sp nov., Microvirga lotononidis sp nov and Microvirga zambiensis sp nov are alphaproteobacterial root-nodule bacteria that specifically nodulate and fix nitrogen with geographically and taxonomically separate legume hosts. Int J Syst Evol Microbiol 62, 2579-2588.

Bae, S., Fleet, G.H. and Heard, G.M. (2006) Lactic acid bacteria associated with wine grapes from several Australian vineyards. J Appl Microbiol 100, 712-727.

Baffoni, L., Gaggia, F., Dalanaj, N., Prodi, A., Nipoti, P., Pisi, A., Biavati, B. and Di Gioia, D. (2015) Microbial inoculants for the biocontrol of Fusarium spp. in durum wheat. BMC Microbiol 15, 242.

Baldi, E., Toselli, M., Marcolini, G., Quartieri, M., Cirillo, E., Innocenti, A. and Marangoni, B. (2010) Compost can successfully replace mineral fertilizers in the nutrient management of commercial peach orchard. Soil Use Manag 26, 346-353.

Baskar, P. and Shanmugham, P.M. (2016) Performance of chillies-sunflower cropping system under organic nutrient management. Int J Agric Stat Sci 12, 193-196.

Bengtsson-Palme, J., Ryberg, M., Hartmann, M., Branco, S., Wang, Z., Godhe, A., De Wit, P., Sanchez-Garcia, M. et al. (2013) Improved software detection and extraction of ITS1 and ITS2 from ribosomal ITS sequences of fungi and other eukaryotes for analysis of environmental sequencing data. Methods Eco Evol 4, 914-919.

Bengtsson-Palme, J., Hartmann, M., Eriksson, K.M., Pal, C., Thorell, K., Larsson, D.G.J. and Nilsson, R.H. (2015) metaxa2: improved identification and taxonomic classification of small and large subunit rRNA in metagenomic data. Mol Ecol Resour 15, 1403-1414.

Burns, K.N., Bokulich, N.A., Cantu, D., Greenhut, R.F., Kluepfel, D.A., O'Geen, A.T., Strauss, S.L. and Steenwerth, K.L. (2016) Vineyard soil bacterial diversity and composition revealed by $16 \mathrm{~S}$ rRNA genes: differentiation by vineyard management. Soil Biolo Biochem 103, 337348.

Burruano, S., Mondello, V. and Conigliaro, G. (2016) Endophytic fungi in asymptomatic Vitis vinifera L. and their effects on Plasmopara viticola. In Biocontrol of Major Grapevine Diseases: Leading Research ed. Compant, S and Mathieu, F. p. 233. Oxfordshire: CAB International.

Caporaso, J.G., Kuczynski, J., Stombaugh, J., Bittinger, K., Bushman, F.D., Costello, E.K., Fierer, N., Pena, A.G. et al. (2010) QIIME allows analysis of high-throughput community sequencing data. Nat Methods 7, 335-336. 
Carmaran, C.C., Berretta, M., Martinez, S., Munaut, V.B.F. and Gasoni, L. (2015) Species diversity of Cladorrhinum in Argentina and description of a new species, Cladorrhinum australe. Mycolo Prog 14, 94.

Carpenter-Boggs, L., Kennedy, A.C. and Reganold, J.P. (2000) Organic and biodynamic management: effects on soil biology. Soil Sci Soc Am J 64, 1651-1659.

Chalker-Scott, L. (2013) The science behind biodynamic preparations: a literature review. Horttechnology 23, 814819.

Ciccolini, V., Ercoli, L., Davison, J., Vasar, M., Opik, M. and Pellegrino, E. (2016) Land-use intensity and host plant simultaneously shape the composition of arbuscular mycorrhizal fungal communities in a Mediterranean drained peatland. FEMS Microbiol Ecol 92, pii: fiw186. Epub 2016 Sep 7.

Coll, P., Le Cadre, E., Blanchart, E., Hinsinger, P. and Villenave, C. (2011) Organic viticulture and soil quality: a long-term study in Southern France. Appl Soil Ecol 50, 37-44.

Corneo, P.E., Pellegrini, A., Cappellin, L., Roncador, M., Chierici, M., Gessler, C. and Pertot, I. (2013) Microbial community structure in vineyard soils across altitudinal gradients and in different seasons. FEMS Microbiol Ecol 84, 588-602.

Council Regulation (EC) No 834/2007. (2007) On organic production and labelling of organic products and repealing Regulation (EEC) No 2092/91. Off J Eur Union 189: 1-23, http://eur-lex.europa.eu/LexUriServ/LexUriSe rv.do?uri=OJ:L:2007:189:0001:0023:EN:PDF

De Caceres, M. and Legendre, P. (2009) Associations between species and groups of sites: indices and statistical inference. Ecology 90, 3566-3574.

Doring, J., Frisch, M., Tittmann, S., Stoll, M. and Kauer, R. (2015) Growth, yield and fruit quality of grapevines under organic and biodynamic management. PLoS ONE 10, e0138445.

Edgar, R.C. (2013) UPARSE: highly accurate OTU sequences from microbial amplicon reads. Nat Methods 10, 996-998.

Edgar, R.C., Haas, B.J., Clemente, J.C., Quince, C. and Knight, R. (2011) UCHIME improves sensitivity and speed of chimera detection. Bioinformatics 27, 2194-2200.

El-Tarabily, K.A., Hardy, G.E.S. and Sivasithamparam, K. (2010) Performance of three endophytic actinomycetes in relation to plant growth promotion and biological control of Pythium aphanidermatum, a pathogen of cucumber under commercial field production conditions in the United Arab Emirates. Eur J Plant Pathol 128, 527-539.

Fierer, N., Bradford, M.A. and Jackson, R.B. (2007) Toward an ecological classification of soil bacteria. Ecology 88, 13541364.

Filonow, A.B. and Lockwood, J.L. (1985) Evaluation of several actinomycetes and the fungus Hyphochytrium-catenoides as biocontrol agents for Phythophthora root-rot of soybean. Plant Dis 69, 1033-1036.
Franke-Whittle, I.H., Manici, L.M., Insam, H. and Stres, B. (2015) Rhizosphere bacteria and fungi associated with plant growth in soils of three replanted apple orchards. Plant Soil 395, 317-333.

Gajbhiye, M.H. and Kapadnis, B.P. (2016) Antifungal-activityproducing lactic acid bacteria as biocontrol agents in plants. Biocontrol Sci Technol 26, 1451-1470.

Gardes, M. and Bruns, T.D. (1993) ITS primers with enhanced specificity for basidiomycetes - Application to the identification of mycorrhizae and rusts. Mol Ecol 2, 113118.

Gaspar, J.M. and Thomas, W.K. (2015) FlowClus: efficiently filtering and denoising pyrosequenced amplicons. BMC Bioinformatics 16, 105.

Grady, E.N., MacDonald, J., Liu, L., Richman, A. and Yuan, Z.C. (2016) Current knowledge and perspectives of Paenibacillus: a review. Microb Cell Fact 15, 203.

Guzzon, R., Gugole, S., Zanzotti, R., Malacarne, M., Larcher, R., von Wallbrunn, C. and Mescalchin, E. (2016) Evaluation of the oenological suitability of grapes grown using biodynamic agriculture: the case of a bad vintage. $J$ Appl Microbiol 120, 355-365.

Haidar, R., Deschamps, A., Roudet, J., Calvo-Garrido, C., Bruez, E., Rey, P. and Fermaud, M. (2016) Multi-organ screening of efficient bacterial control agents against two major pathogens of grapevine. Biol Control 92, 55-65.

Hartmann, M., Frey, B., Mayer, J., Mäder, P. and Widmer, F. (2015) Distinct soil microbial diversity under long-term organic and conventional farming. The ISME J. 9, 11771194.

Hayatsu, M., Tago, K. and Saito, M. (2008) Various players in the nitrogen cycle: diversity and functions of the microorganisms involved in nitrification and denitrification. Soil Sci. Plant Nutr. 54, 33-45.

Hervé, M. (2017) Diverse basic statistical and graphical functions. R package version 0.9-64. https://CRANR-projec torg/package $=$ RVAideMemoire

Hop, D.V., Sakiyama, Y., Chu, T.T.B., Otoguro, M., Hang, D.T., Miyadoh, S., Luong, D.T. and Ando, K. (2011) Taxonomic and ecological studies of actinomycetes from Vietnam: isolation and genus-level diversity. J Antibiot 64, 599-606.

Hothorn, T., Bretz, F. and Westfall, P. (2008) Simultaneous inference in general parametric models. Biom J 50, 346363.

Ingels, C.A., Scow, K.M., Whisson, D.A. and Drenovsky, R.E. (2005) Effects of cover crops on grapevines, yield, juice composition, soil microbial ecology, and gopher activity. Am J Enol Vitic 56, 19-29.

Irvin, N.A., Pinckard, T.R., Perring, T.M. and Hoddle, M.S. (2014) Evaluating the potential of buckwheat and cahaba vetch as nectar producing cover crops for enhancing biological control of Homalodisca vitripennis in California vineyards. Biol Control 76, 10-18. 
Kirchmann, H. (1994) Biological dynamic farming - An occult form of alternative agriculture. J AgricEnviron Ethics 7, 173-187.

Koch, H., Lucker, S., Albertsen, M., Kitzinger, K., Herbold, C., Spieck, E., Nielsen, P.H., Wagner, M. et al. (2015) Expanded metabolic versatility of ubiquitous nitriteoxidizing bacteria from the genus Nitrospira. Proc Natl Acad Sci USA 112, 11371-11376.

Komarek, M., Cadkova, E., Chrastny, V., Bordas, F. and Bollinger, J.C. (2010) Contamination of vineyard soils with fungicides: a review of environmental and toxicological aspects. Environ Int 36, 138-151.

Linkind, D., Gadanho, M., van Broock, M. and Sampaio, J.P. (2009) Cystofilobasidium lacus-mascardii sp nov., a basidiomycetous yeast species isolated from aquatic environments of the Patagonian Andes, and Cystofilobasidium macerans sp nov., the sexual stage of Cryptococcus macerans. Int J Syst Evol Microbiol 59, 622630.

Lisboa, F.J.G., Peres-Neto, P.R., Chaer, G.M., Jesus, E.D., Mitchell, R.J., Chapman, S.J. and Berbara, R.L.L. (2014) Much beyond Mantel: bringing procrustes association metric to the plant and soil ecologist's toolbox. PLOS ONE 9, e101238.

Lopez-Pineiro, A., Albarran, A., Nunes, J.M.R., Pena, D. and Cabrera, D. (2011) Long-term impacts of de-oiled twophase olive mill waste on soil chemical properties, enzyme activities and productivity in an olive grove. Soil Tillage Res 114, 175-182.

Lotter, D.W. (2003) Organic agriculture. J Sustain Agr 21, 59 128.

Miguens, T., Leiros, M.C., Gil-Sotres, F. and Trasar-Cepeda, C. (2007) Biochemical properties of vineyard soils in Galicia, Spain. Sci Total Environ 378, 218-222.

Munoz, A., Lopez-Pineiro, A. and Ramirez, M. (2007) Soil quality attributes of conservation management regimes in a semi-arid region of south western Spain. Soil Tillage Res 95, 255-265.

Muyzer, G., Dewaal, E.C. and Uitterlinden, A.G. (1993) Profiling of complex microbial-populations by denaturing gradient gel electrophoresis analysis of polymerase chain reaction-amplified genes coding for $16 \mathrm{~S}$ ribosomal-RNA. Appl Environ Microbiol 59, 695-700.

Nicola, L., Turco, E., Albanese, D., Donati, C., Thalheimer, M., Pindo, M., Insam, H., Cavalieri, D. et al. (2017) Fumigation with dazomet modifies soil microbiota in apple orchards affected by replant disease. Appl Soil Ecol 113, 71-79.

Nisiotou, A.A., Dourou, D., Filippousi, M.E., Diamantea, E., Fragkoulis, P., Tassou, C. and Banilas, G. (2015) Genetic and technological characterisation of vineyard- and wineryassociated lactic acid bacteria. Biomed Res Int 2015, 508254.

Nurkanto, A., Lisdiyanti, P., Hamada, M., Ratnakomala, S., Shibata, C. and Tamura, T. (2016) Actinoplanes bogoriensis sp nov., a novel actinomycete isolated from leaf litter. J Antibioti 69, 26-30.

Oksanen, J., Blanchet, F.G., Friendly, M., Kindt, R., Legendre, P., McGlinn, D., Minchin, P.R., O'Hara, R.B. et al. (2017) vegan: community ecology package. $\mathrm{R}$ package version 2.4-2. https://CRANR-projectorg/package=vegan

Okur, N., Kayikcioglu, H.H., Ates, F. and Yagmur, B. (2016) A comparison of soil quality and yield parameters under organic and conventional vineyard systems in Mediterranean conditions (West Turkey). Biol Agric Hortic 32, 73-84.

Orgiazzi, A., Lumini, E., Nilsson, R.H., Girlanda, M., Vizzini, A., Bonfante, P. and Bianciotto, V. (2012) Unravelling soil fungal communities from different Mediterranean landuse backgrounds. PLoS ONE 7, e3487.

Peintner, U., Knapp, M., Fleischer, V., Walch, G. and Dresch, P. (2016) Myrmecridium hiemale sp nov from snowcovered alpine soil is the first eurypsychrophile in this genus of anamorphic fungi. Int J Syst Evol Microbiol 66, 2592-2598.

Probst, B., Schuler, C. and Joergensen, R.G. (2008) Vineyard soils under organic and conventional management Microbial biomass and activity indices and their relation to soil chemical properties. Biol Fertil Soils 44, 443-450.

Quast, C., Pruesse, E., Yilmaz, P., Gerken, J., Schweer, T., Yarza, P., Peplies, J. and Glockner, F.O. (2013) The SILVA ribosomal RNA gene database project: improved data processing and web-based tools. Nucleic Acids Res 41, D590-D596.

Reeve, W., Ardley, J., Tian, R., De Meyer, S., Terpolilli, J., Melino, V., Tiwari, R., Yates, R. et al. (2014) Genome sequence of the Listia angolensis microsymbiont Microvirga lotononidis strain WSM3557(T). Stand Genomic Sci 9, 540-550.

Rotaru, L., Stoleru, V. and Mustea, M. (2011) Fertilization with green manure on Chasselas Dore grape vine as an alternative for sustainable viticulture. J Food Agric Environ 9, 236-243.

Sarookhani, M.R. and Moazzami, N. (2007) Isolation of Acremonium species producing cephalosporine $\mathrm{C}(\mathrm{CPC})$ from forest soil in Gilan province, Iran. Afri J Biotechnol 6, 2506-2510.

Schimel, J.P. and Schaeffer, S.M. (2012) Microbial control over carbon cycling in soil. Front Microbiol 3, 348.

Schlegel, W. (1973) Der Weinbau in der Schweiz, pp 24-92. Wiesbaden: Steiner.

Schmieder, R. and Edwards, R. (2011) Quality control and preprocessing of metagenomic datasets. Bioinformatics 27, 863-864.

Schreiner, R.P. and Mihara, K.L. (2009) The diversity of arbuscular mycorrhizal fungi amplified from grapevine roots (Vitis vinifera L.) in Oregon vineyards is seasonally stable and influenced by soil and vine age. Mycologia 101, 599-611. 
Seyedmousavi, S., Netea, M.G., Mouton, J.W., Melchers, W.J.G., Verweij, P.E. and de Hoog, G.S. (2014) Black yeasts and their filamentous relatives: principles of pathogenesis and host defense. Clin Microbiol Rev 27, 527-542.

Singh, B., Pocas-Fonseca, M.J., Johri, B.N. and Satyanarayana, T. (2016) Thermophilic molds: biology and applications. Crit Rev Microbiol 42, 985-1006.

Srinivasan, S., Lee, J.J., Lee, S.S. and Kim, M.K. (2014) Pontibacter humi sp. nov, isolated from mountain soil. Curr Microbiol 69, 263-269.

Steenwerth, K.L., Drenovsky, R.E., Lambert, J.J., Kluepfel, D.A., Scow, K.M. and Smart, D.R. (2008) Soil morphology, depth and grapevine root frequency influence microbial communities in a Pinot noir vineyard. Soil Biol Biochem 40, 1330-1340.

Sterflinger, K. (2006) Black yeasts and meristematic fungi: ecology, diversity and identification. In Biodiversity and Ecophysiology of Yeasts Part of the Series the Yeast Handbook ed. Peter, G., Rosa, C. and Leao, C. pp. 501514. Heidelberg, Berlin: Springer Berlin.

Stockinger, H., Kruger, M. and Schussler, A. (2010) DNA barcoding of arbuscular mycorrhizal fungi. New Phytol 187, 461-474.

Sugiyama, A., Vivanco, J.M., Jayanty, S.S. and Manter, D.K. (2010) Pyrosequencing assessment of soil microbial communities in organic and conventional potato farms. Plan Dis 94, 1329-1335.

Villanueva-Rey, P., Vazquez-Rowe, I., Moreira, M.O.T. and Feijoo, G. (2014) Comparative life cycle assessment in the wine sector: biodynamic vs. conventional viticulture activities in NW Spain. J Clean Prod 65, 330-341.

Wang, Q., Garrity, G.M., Tiedje, J.M. and Cole, J.R. (2007) Naive Bayesian classifier for rapid assignment of rRNA sequences into the new bacterial taxonomy. Appl Environ Microbiol 73, 5261-5267.

Weisburg, W.G., Barns, S.M., Pelletier, D.A. and Lane, D.J. (1991) 16S ribosomal DNA amplification for phylogenetic study. J Bacteriol 173, 697-703.

White, T.J., Bruns, T., Lee, S., Taylor, J. (1990) Amplification and direct sequencing of fungal ribosomal RNA genes for phylogenetics. In: PCR Protocols. A Guide to Methods and Applications ed. Innis, M.A., Gelfand, G.H., Sninsky, J.J., White, T.J. p. 315-322. New York: Academic press.

Wittwer, R.A., Dorn, B., Jossi, W. and dervan Heijden, M.G.A. (2017) Cover crops support ecological intensification of arable cropping systems. Sci Rep 7, 41911.
Xu, L.H., Zeng, X.C., Nie, Y., Luo, X.S., Zhou, E.M., Zhou, L.L., Pan, Y.F. and Li, W.J. (2014) Pontibacter diazotrophicus sp nov., a Novel Nitrogen-Fixing Bacterium of the Family Cytophagaceae. PLoS ONE 9, e92294.

Zhou, X., Fornara, D., Wasson, E.A., Wang, D.M., Ren, G.D., Christie, P. and Jia, Z.J. (2015) Effects of 44 years of chronic nitrogen fertilization on the soil nitrifying community of permanent grassland. Soil Biol Biochem 91, 76-83.

\section{Supporting Information}

Additional Supporting Information may be found in the online version of this article:

Figure S1. Rarefaction curves indicating the observed number of operational taxonomic units (OTUs) related to the number of sequences retrieved in each of the different soil vineyard managements with $16 \mathrm{~S}$ primer set. $\mathrm{O}$, samples from organically managed soil; $\mathrm{BD}$, samples from biodynamically managed soil; BDGM, samples from biodynamically managed soil with the addition of green manure. The solid line and the dashed line represent, respectively, samples from Fields 1 and 2.

Figure S2. Rarefaction curves indicating the observed number of operational taxonomic units (OTUs) related to the number of sequences retrieved in each of the different soil vineyard managements with ITS primer set. O, samples from organically managed soil; $\mathrm{BD}$, samples from biodynamically managed soil; BDGM, samples from biodynamically managed soil with the addition of green manure. The solid line and the dashed line represent, respectively, samples from Field 1 and 2 .

Table S1. Alpha-diversity analysis for bacteria and fungi calculated with a generalized linear model (GLM) and Tukey contrasts as post hoc analysis.

Table S2. Beta-diversity analysis for bacteria and fungi calculated with PERMANOVA on Bray-Curtis dissimilarities and permutational pairwise comparisons.

Table S3. Differentially abundant bacterial genera calculated with permutational ANOVA.

Table S4. Differentially abundant fungal genera calculated with permutational ANOVA. 